\title{
LPCVD of SiC layers in a hot-wall reactor using TMS precursor
}

\author{
F. HENRY, P. MARTI*, Y. CASAUX, C. COMBESCURE, A. FIGUERAS ${ }^{* *}$, V. MADIGOU**, \\ R. RODRIGUEZ-CLEMENTE** A. MAZEL ${ }^{*}$, J. SEVELY* and B. ARMAS
}

Institut de Science et de Génie des Matériaux et Procédés, CNRS, BP. 5, Odeillo, 66125 Font Romeu cedex, France

* Centre d'Elaboration des Matériaux et d'Etudes Structurales, Laboratoire d'Optique Electronique, CNRS, BP. 4347, 31055 Toulouse cedex, France

** Institut de Ciencia de Materials de Barcelona, CSIC, Campus de la UAB, 08193 Cerdanyola, Spain

\section{ABSTRACT}

Sic polycrystalline layers were grown by LPCVD in a hot wall reactor using tetramethylsilane (TMS) diluted in hydrogen as precursor.

The morphology and the structure of the films were analyzed in terms of deposition temperature, total pressure in the reactor and TMS flow rate.

The layers have been characterized using various techniques: SEM, X-ray diffraction and TEM (HREM and EELS).

\section{INTRODUCTION}

silicon carbide has attracted considerable interest in several fields of science and technology because of its outstanding thermochemical properties, in particular its high thermal and chemical stability [1].

$\mathrm{SiC}$ is also a semiconductor with remarkable physical properties such as a wide band-gap energy (ranging from $2.2 \mathrm{eV}$ for $\beta-\mathrm{sic}$ to 3.3 $\mathrm{eV}$ for $2 \mathrm{H}-\alpha-\mathrm{SiC})$, high electron mobility $\left(1000 \mathrm{~cm}^{2} / \mathrm{V} . \mathrm{s}\right)$ and high drift velocity (about $10^{7} \mathrm{~cm} / \mathrm{s}$ ). These physical properties show that Sic is a potentially useful material for electronic devices operating under severe conditions such as high temperatures and oxidizing atmospheres.

Chemical Vapour Deposition (CVD) is one of the most attractive techniques for preparing SiC films, because the material is directly obtained by thermal decomposition of raw gases. Alkyl-silicon compounds are potentially useful as CVD source gases. They are effective because $\mathrm{Si}-\mathrm{C}$ bonds are already preformed in the precursors [3].

This paper deals with the morphological and structural characterization of polycrystalline layers of Sic grown on graphite substrates in a hot-wall reactor, using the decomposition of tetramethylsilane (TMS) and hydrogen as carrier gas, by scanning electron microscopy (SEM) and $X$-ray diffraction (XRD). The microstructure and chemical composition of the layers was studied by analytical transmission electron microscopy (TEM) including high resolution observations (HREM) and electron energy loss spectroscopy (EELS). 


\section{ELABORATION OF THE COATINGS}

A vertical hot-wall CVD reactor was used consisting of a graphite reaction chamber of cylindrical geometry ( $\Phi=44 \mathrm{~mm}, \mathrm{~h}=80 \mathrm{~mm})$. It was heated by RF induction with a power supply operating at 140 $\mathrm{kHz}$. A polycrystaliine graphite substrate was placed in the reaction chamber normal to the direction of the gas flow. The temperature of the reaction chamber ranged from 950 to $1400^{\circ} \mathrm{C}$ and was measured with an optical pyrometer. The total pressure in the reactor (P) was controlled by a "MKS Baratron" gauge and was regulated using a valve connected to the vacuum system. The gas flows were controlled by mass-flow controllers. For these experiments, the $\mathrm{H}_{2}$ flow rate, $\Phi_{\mathrm{H} 2}$, was held constant at $100 \mathrm{sccm}$. The TMS flow rates, $\Phi_{T M S}$, had two values, 4 and $10 \mathrm{sccm}$. The experiments were performed at two reduced pressures: 66 and $133 \mathrm{~Pa}$.

\section{CHARACTERIZATION OF THE COATINGS}

\subsection{SEM and $X$-ray results}

The morphology of Sic films obtained by CVD strongly depends on process parameters such as deposition temperature, TMS flow, and total pressure in the reactor.

Figure 1 shows the evolution of the layer morphology as a function of TMS flow and total pressure in the reactor at $T=1230^{\circ} \mathrm{C}$. At loW $\Phi_{T M S}$, the films are fine-grained and compact. At $P_{T M S}=2.54 \mathrm{~Pa}$, the layers exhibit well facetted crystals ( $3 \mu \mathrm{m}$ in size) (fig.la), while at $P_{T M S}=5.11 \mathrm{~Pa}$, the crystal morphology becomes less well defined (fig. 1c). An increase in TMS partial pressure, $P_{T M S}$, results in the formation of spherulites of different sizes. They are about 40 $\mu \mathrm{m}$ in size at $\mathrm{P}_{T M S}=6 \mathrm{~Pa}$ (fig. $1 \mathrm{~b}$ ) and about $8 \mu \mathrm{m}$ at $\mathrm{P}_{T M S}=12 \mathrm{~Pa}$ ( $\mathrm{fig}$. 1d). As shown by SEM micrograph reproduced on figure $1 \mathrm{~b}$ the spherulites are composed of facetted crystals. The films obtained at deposition temperature between 1300 and $1380^{\circ} \mathrm{C}$ present a changing morphology. The coatings are composed of individual pseudohexagonal pyramidal structures normal to the substrate surface (fig. 2). Above $\mathrm{T}=1400^{\circ} \mathrm{C}$, the individual pseudohexagonal structures disappear and $\mathrm{a}$ disordered porous layer with some well defined crystals is observed (fig. 3).

The structural characterization was performed by X-ray powder diffraction. This technique allows us to determine the crystalline planes parallel to the substrate surface (preferential orientation). The order in other directions should be studied by rocking curves [4] or texture diagrams.

The films deposited at $\mathrm{T}=1230^{\circ} \mathrm{C}, \mathrm{P}=66 \mathrm{~Pa}$ and $\Phi_{\mathrm{TMS}}=4 \mathrm{sccm}$ exhibit $\mathrm{X}$-ray diffraction diagrams corresponding to the cubic $\beta-S i C$ structure with a strong preferential orientation along the [110] direction. This preferential orientation changed to [111] when $\Phi_{T M S}$ changed to $10 \mathrm{sccm}$. All films obtained at temperatures between 1300 and $1380^{\circ} \mathrm{C}$ show a strong preferential orientation along the [111] direction. At temperatures above $T=1400^{\circ} \mathrm{C}$ the preferential orientation disappears leading to a powder diffractogram pattern.

\subsection{TEM results}

This study has been focused order to understand more precisely the effect of the deposition 
temperature on the structure of the layers. The samples, obtained at $1320^{\circ} \mathrm{C}$ and $1400^{\circ} \mathrm{C}$ respectively, have been studied from the structural and chemical point of view. Transmission electron microscopy studies have been performed with a Philips CM30 ST equipped with a GATAN 666 spectrometer operating at $300 \mathrm{kV}$. The samples were thinned by mechanical polishing followed by $\mathrm{Ar}^{+}$ion milling. The conventional dark-field images reproduced on figures $4 \mathrm{a}$ and $4 \mathrm{~b}$ clearly show the change in the structure of the material when the deposition temperature increases.

At the lower temperature value, $1320^{\circ} \mathrm{C}$, the continuous streaking of reflections observed on the electron diffraction pattern reproduced on figure $4 \mathrm{a}$ indicates that this material is constituted by a disordered stacking along the growing direction of the Si-C elementary layers. The dark field image obtained by selecting the arrowed diffraction spot allows the disordered arrangement of the layers to be clearly observed.

The conventional TEM observations of the layers obtained at $1400^{\circ} \mathrm{C}$ shows that $\beta-S i C$ is heavily twinned. Extra spots due to the twins can easily be observed on the electron diffraction pattern reproduced on figure $4 \mathrm{~b}$ and corresponding to a [110] incident beam direction. The dark-field image associated with the arrowed reflection reveals the distribution of twins in the crystal. It has been found that many crystals have the perfect $z$ incblende structure of the $\beta-$ SiC. This result is illustrated by the high resolution image reproduced on figure 5 .

Chemical analysis performed by EELS has confirmed that the Sic crystals in the deposits are stoichiometric. An atomic ratio si/C close to 1 has been measured for all the analyzed areas. These values result from the classical quantitative treatment of the EELS spectra as proposed by EGERTON [5]. Figure 6a shows an example of the Si L-edge and $C$ K-edge distributions which are considered for this evaluation. The position of the plasmon peak in the EELS spectrum is measured at $22.6 \mathrm{eV}$ which confirms the stoichiometric Sic composition [6]. In the case of the sample obtained at $1400^{\circ} \mathrm{C}, \mathrm{Fig.7}$, crystallized areas (b) have also been observed quasi-systematically around the SiC crystals (a). An EELS analysis of these areas revealed that they are essentially constituted by carbon (figure 6b). This is confirmed by the broad peak centered at $26.6 \mathrm{eV}$ corresponding to the volume plasmon and the $K$ inner-shell excitation edge observed at 285 eV [6].

\section{DISCUSSION AND CONCLUSION}

The evolution of the film morphology with the increase of TMS flow rate can be explained in terms of the increase of supersaturation in the system (related to the partial pressure of the precursors), and the different kinetics of growth of the three morphologically more important forms $\{100\},\{111\}$ and $\{111\}$ of $\beta-$ Sic.

\subsection{TMS FLOW EFFECTS}

At $\Phi_{T M S}=4$ sccm, heterogeneous nucleation of small crystallites leads to homogeneous coatings showing a preferential orientation along [110]. This orientation results from a crystal growth rate of the form $\{100\}$ higher than the two other forms $\{111\}$ and $\{111\}$. This fact could be explained by the high concentration of hydrogen 
$\left(\mathrm{P}_{\mathrm{H} 2} / \mathrm{P}_{\mathrm{TMS}}=24\right)$ and low concentration of pyrolysis products (impurities: $\mathrm{C}_{2} \mathrm{H}_{4}, \mathrm{C}_{2} \mathrm{H}_{2}, \ldots$ ) [7] that allow the highly reactive cube polar faces $(100),(010),(001)$ (included in the $\{100\}$ morphological form) to grow faster than the non polar faces of the tetrahedra $\{111\}$ and $\{111\}$. Under these assumptions, [111] should be the faster growth direction (corner), because it corresponds to the composition of the normal to three fast growth faces. Nevertheless, this "corner direction" is blocked by the presence of $\{111\}$ and $\{111\}$ faces. Consequently, the higher rate of growth of the form $\{100\}$ results in a preferential orientation along [110] because it is the edge between two faces of this form. At $\mathrm{P}=133 \mathrm{~Pa}$, the orientation is less accentuated because the film surface is rougher and the crystals tend to form "rosettes".

The deposition rate strongly increases with $\Phi_{\mathrm{TMS}}$. Consequently, the tiny nucleated crystallites tend to agglomerate to form spherulites. The spherulites obtained at $\Phi_{\text {TM }}=10 \mathrm{sccm}$ have different sizes as a function of the total pressure in the reactor. Furthermore, the augmentation of TMS flow leads to a relative diminution of hydrogen partial pressure $\left(\mathrm{P}_{\mathrm{H}_{2}} / \mathrm{P}_{\mathrm{TMS}}=10\right)$ and an increase in the concentration of impurities [7] which contaminate and probably block the more reactive faces corresponding to the $\{100\}$ morphological form. Thus, a higher rate of growth of both $\{111\}$ and \{111\} forms results in a preferential orientation along the [111] direction. At $\mathrm{P}=133 \mathrm{~Pa}$, homogeneous nucleation starts and consequently, the diffraction pattern looks like a powder diffraction pattern.

\subsection{DEPOSITION TEMPERATURE EFFECT}

The increase in the deposition temperature has four effects :

a) the mobility of the growth units on the surface is favoured

b) the surface roughness increases

c) the desorption of hydrogen and other impurities from the surface is promoted

d) there is an increase in the impurity concentration due to the augmentation in the TMS pyrolysis rate.

The first two effects favour crystal growth and result in a crystal morphology bounded by well-defined facets. The third effect decreases the concentration of hydrogen and other impurities on the surface. In fact, the decrease in the impurity concentration is balanced by the fourth effect. Consequently, the more reactive faces such as $\{100\}$ cannot grow faster than $\{111\}$ and $\{111\}$. A preferential crystallization along [111] develops. These mechanisms could explain the morphologies exhibited by the layers deposited at temperatures ranged between 1300 and $1380^{\circ} \mathrm{C}$.

At a working temperature of $1400^{\circ} \mathrm{C}$, we observe an increase in the free carbon concentration in the layers, which prevents the crystals growing, and the film consists of randomly orientated crystallites surrounded by carbon. Consequently, the $x$-ray diffraction pattern corresponds to a randomly oriented $\beta-S i C$ powder diagram. This fact suggests that the formation of these crystallites is a gas phase homogeneous nucleation mechanism. Perhaps the high concentration of free carbon is due to reevaporation of $\mathrm{Si}$. 


\section{ACKNOWLEDGEMENTS}

This work has been partially supported by the French Ministry of Defence, Direction des Recherches et Etudes Techniques (Contrat DRET $N^{\circ} 901197 A$ ), a Spanish CICYT project $N^{\circ}$ MAT468/92 and European contract $\mathrm{N}^{\circ}$ ERBCHBICT920201.

\section{References}

1 - SIBIEUDE F., RODRIGUEZ J., CLAVAGUERA-MORA M.T. Thin Solid Films 204 (1) (1991) 217-227.

2 - ANIKIN M.M., LEBEDEV A.A., PYATKO S.N., STREL'CHUK A.M., SYRKIN A.L. Materials Science and Engineering B II (1992) 113 -115.

3 - AVIGAL Y., SCHIEBER M., LEVIN R. J. of Crystal Growth 24/25 (1974) 188-192.

4 - SANTISO J., FIGUERAS A., RODRIGUEZ-CLEMENTE R., ARMAS B., COMBESCURE C., MAZEL A., KIHN Y., SEVELY J.. J, of Crystal Growth 128 (1993) 363-368.

5 - EGERTON R.F. Electron Energy Loss Spectroscopy in the Electron Microscope, Plenum Press, New York (1986)

6 - RAETHER H. Excitation of Plasmons and Interband Transition by Electrons, Springer Tracts in Modern Physics, Berlin, New York (1980)

7 - VEINTEMILLAS-VERDAGUER S., FIGUERAS A. , RODRIGUEZ-CLEMENTE R. J. of Crystal Growth (1992) in press.

8 - MUEHLOFF L., CHOYKE W.J., BOZACK M.J., YATES J. J. Appl. Phys. (1986) 2842 . 

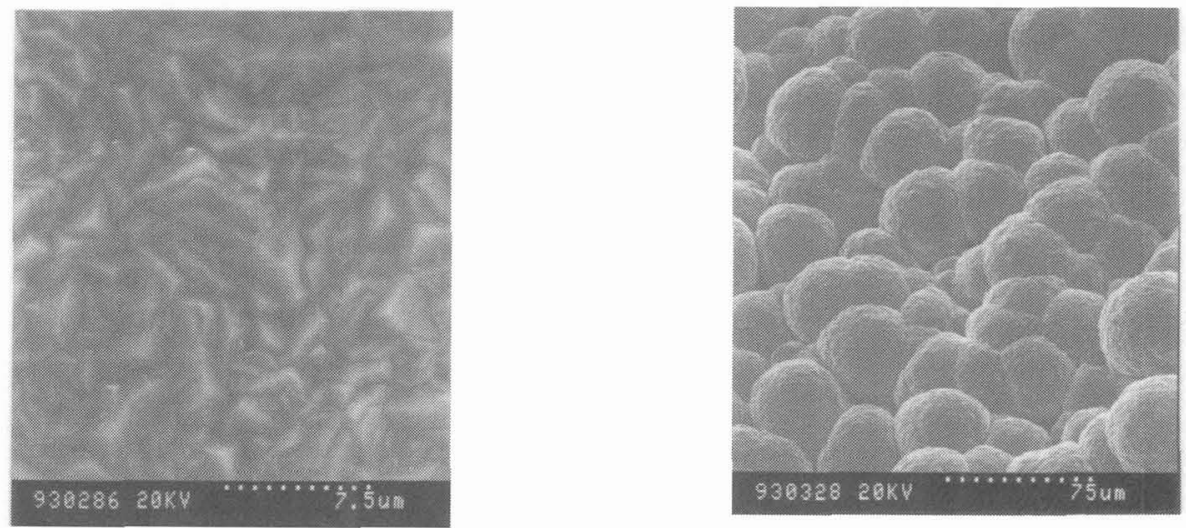

$$
\begin{aligned}
& \mathrm{a}: \Phi_{\mathrm{TMS}}=4 \mathrm{SCCM} \\
& \mathrm{P}=66 \mathrm{~Pa}
\end{aligned}
$$

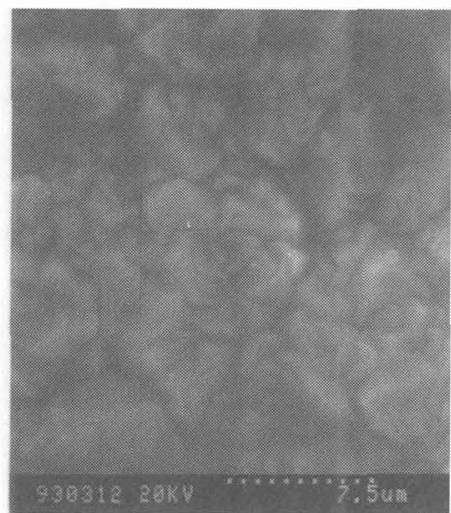

$$
\begin{gathered}
C: \Phi_{T M S}=4 \quad S C C M \\
P=133 \mathrm{~Pa}
\end{gathered}
$$

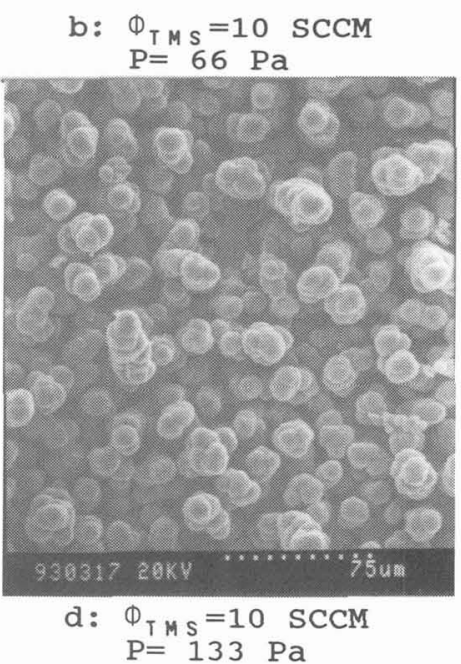

Fig. 1

- SEM micrographs corresponding obtained at $\mathrm{T}=1230^{\circ} \mathrm{C}$

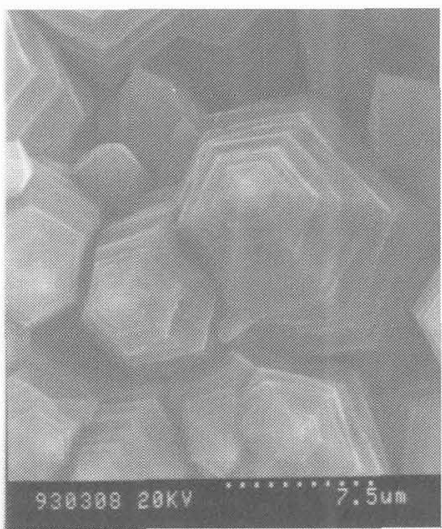

Fig. 2

Surface morphology exhibited by the layers obtained at $\mathrm{T}=1380^{\circ} \mathrm{C}, \mathrm{P}=66 \mathrm{~Pa}, \Phi_{\mathrm{T} \mathrm{S}}=4 \mathrm{SCCM}$ to as grown layers

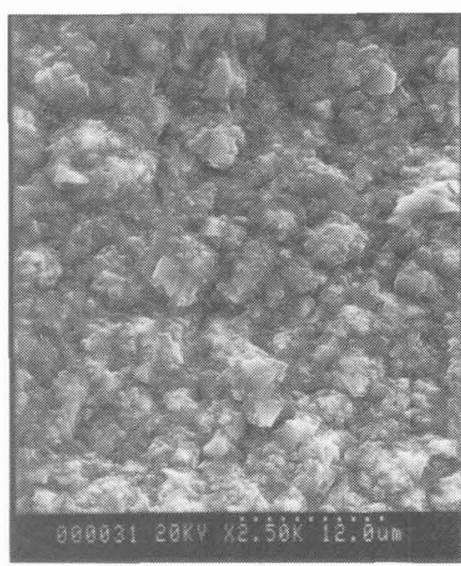

Fig. 3

Surface morphology exhibited by the layers obtained at $\mathrm{T}=1400^{\circ} \mathrm{C}, \mathrm{P}=66 \mathrm{~Pa}, \Phi_{\mathrm{TM} \mathrm{s}}=4 \mathrm{SCCM}$ 

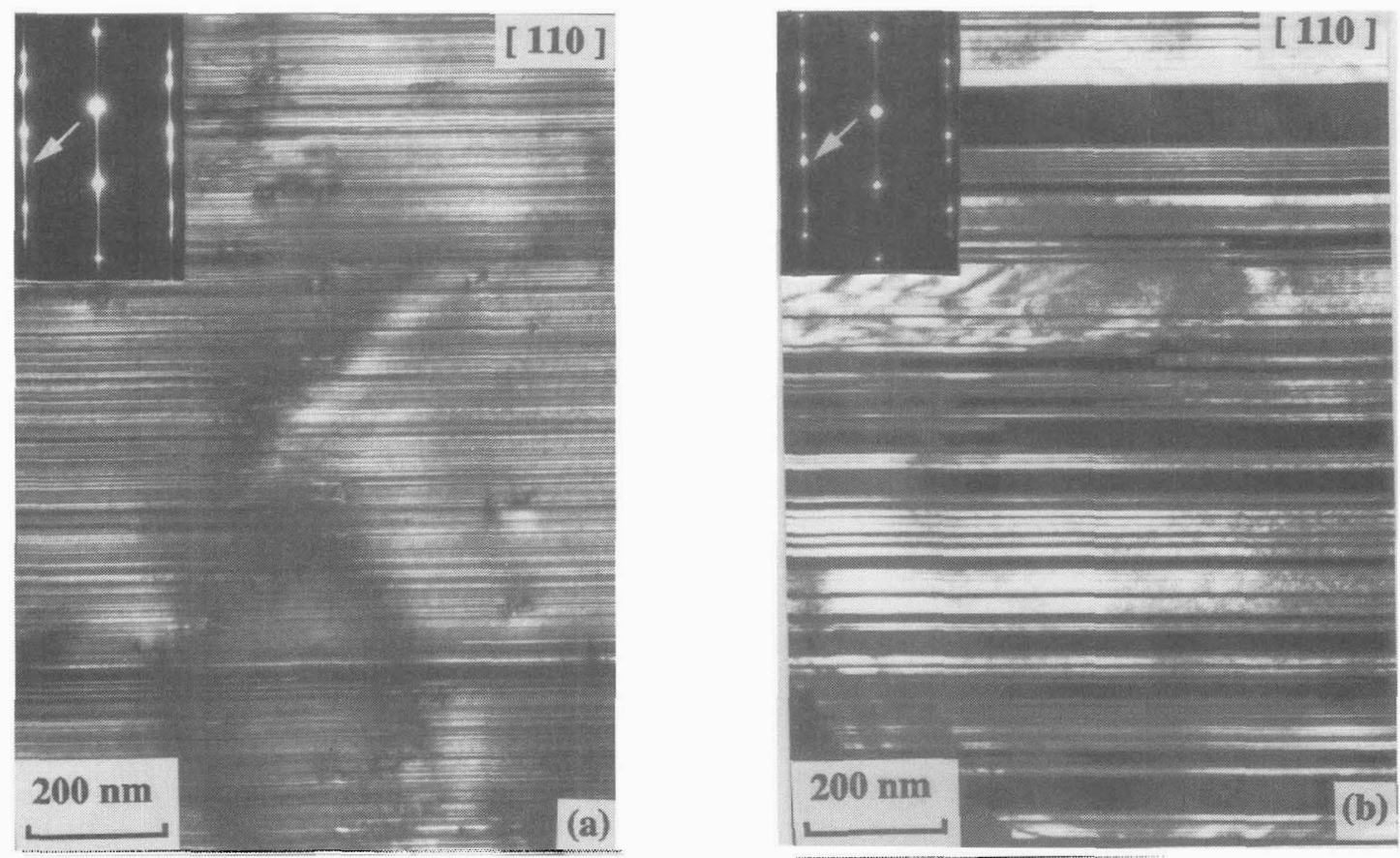

Fig.4- TEM dark-field images and corresponding diffraction patterns of SiC deposits obtained at $\mathrm{T}=1320^{\circ} \mathrm{C}$ (a) and $\mathrm{T}=1400^{\circ} \mathrm{C}$ (b).

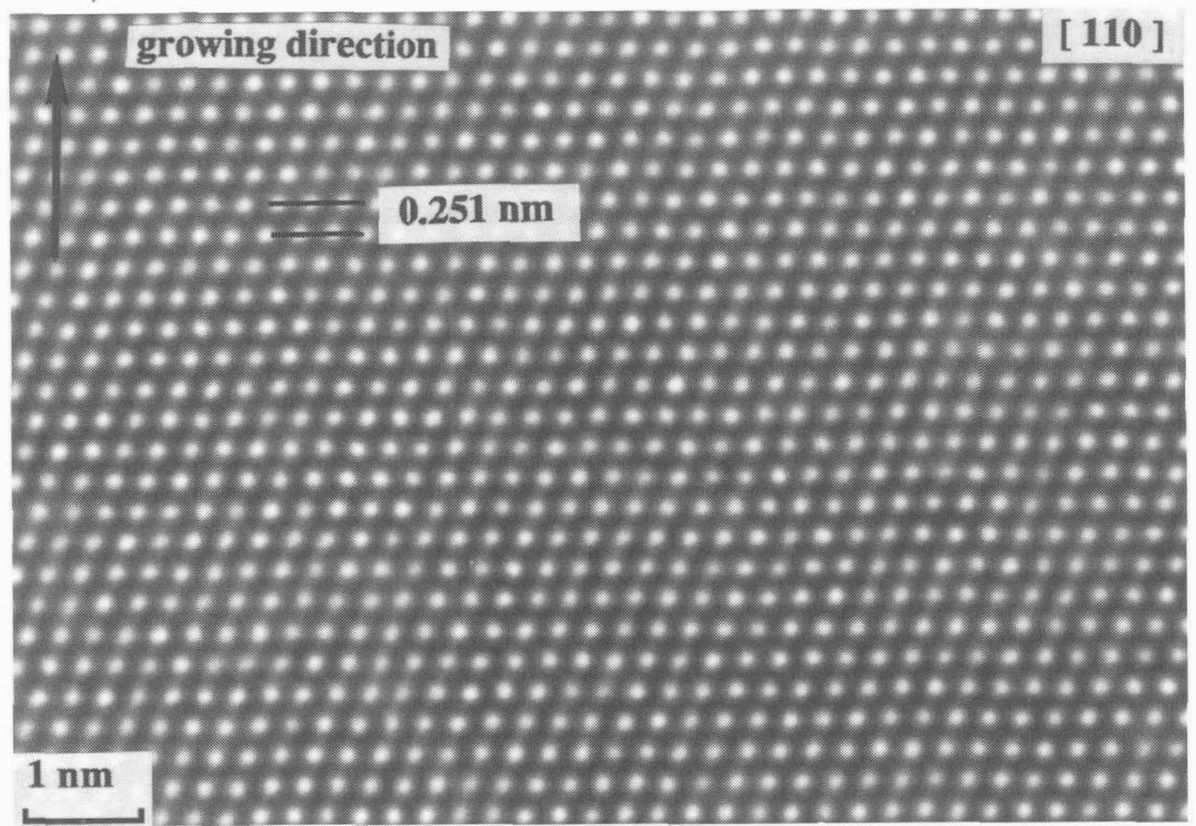

Fig.5- High resolution image of a Sic crystal observed in the [110] orientation. It shows the stacking of the $0.251 \mathrm{~nm}$ distant elementary si-c layers in agreement with the perfect zincblende structure (deposit elaborated at $1400^{\circ} \mathrm{C}$ ) 


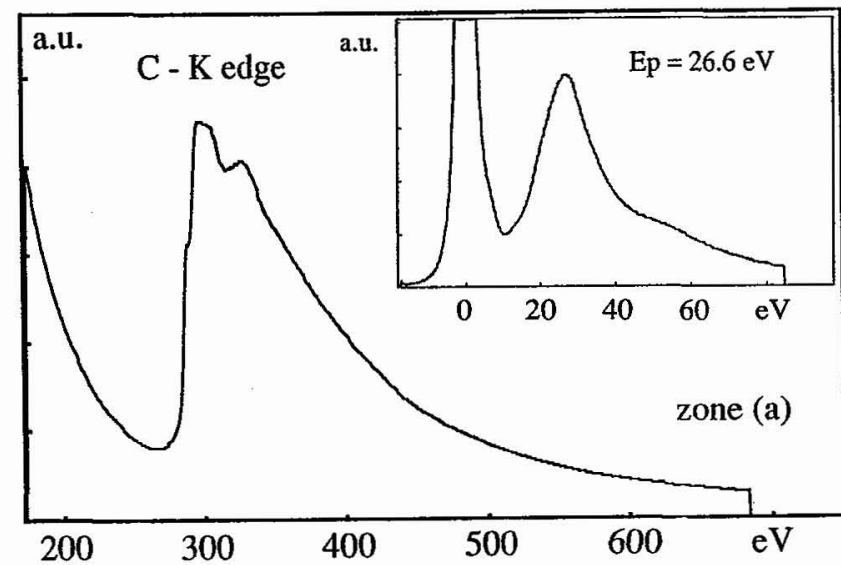

Fig.6a - Electron energy loss spectrum showing the I and $K$ inner-shell distributions related to silicon and carbon respectively and corresponding to zones (a) on figure 7. Insert shows the low energy loss a distribution with plasmon peak at $22.6 \mathrm{ev}$.

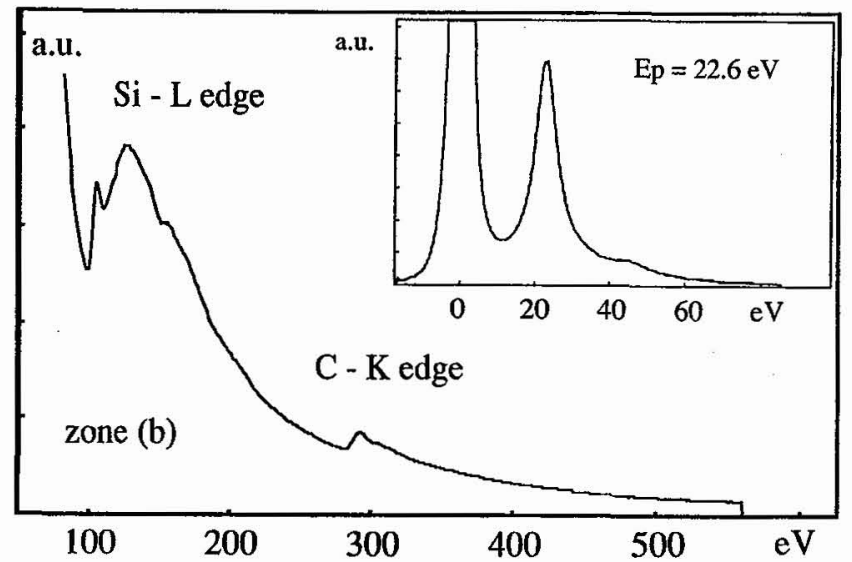

Fig. $6 \mathrm{~b}$ - Electron energy loss spectrum associated to zones(b) on figure 7 . It shows the $K$ inner-shell distribution and the plasmon peak corresponding to carbon

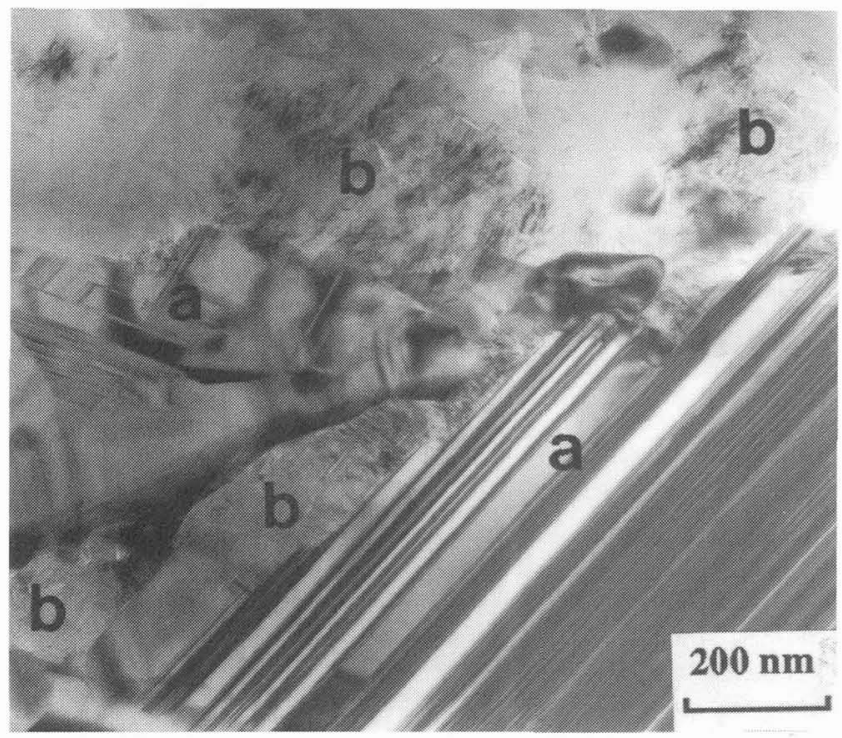

Fig. 7 - TEM bright-field image of a deposit obtained at $1400^{\circ} \mathrm{C}$ showing that SiC crystals (a) are surrounded by crystallized domains (b) identified as carbon by chemical analysis. 